\title{
Cucurbitacin B inhibits cell proliferation and induces cell apoptosis in colorectal cancer by modulating methylation status of BTG3
}

\author{
D. MAO, A. H. LIU, Z. P. WANG, X. W. ZHANG, H. LU* \\ Department of Colorectal Surgery, The First Affiliated Hospital of Jinzhou Medical University, Jinzhou, Liaoning 121001, China \\ ${ }^{*}$ Correspondence: jyfs2018@163.com
}

Received September 29, 2018 / Accepted February 27, 2019

\begin{abstract}
A previous report has revealed that cucurbitacin $\mathrm{B}(\mathrm{CuB})$ inhibits cancer cell proliferation and tumorigenesis in non-small cell lung cancer (NSCLC) through epigenetic modifications of several genes. However, whether CuB regulates cell proliferation and apoptosis by altering methylation status of BTG3 in colorectal cancer (CRC) remains unknown. In the present study, the results showed that BTG3 was downregulated in CRC tissues compared with adjacent normal tissues. $\mathrm{CuB}$ significantly increased BTG3 levels, induced promoter demethylation, decreased the levels of DNA methyltransferases (DNMT1, DNMT3a and DNMT3b) in both CRC cell lines (SW480 and Caco-2) and the effects of CuB were comparable with those of 5-Aza-dC. We also found that $\mathrm{CuB}$ inhibited cell proliferation, accompanied with decreased expression of Ki67. Furthermore, $\mathrm{CuB}$ treatment induced cell cycle arrest at G1 phase in SW480 and Caco-2 cells, as well as decreased levels of Cyclin D1 and Cyclin E1. Incubation with CuB promoted cell apoptosis in both CRC cell lines in vitro, accompanied with elevation of cleaved caspase- 3 and cleaved PARP. BTG3 knockdown abolished the effects of CuB in CRC cells. In summary, $\mathrm{CuB}$-induced proliferation inhibition and cell apoptosis may be due to the reactivation of BTG3 by promoter demethylation. $\mathrm{CuB}$ may be a promising agent for CRC therapy.
\end{abstract}

Key words: cucurbitacin B, BTG3, colorectal cancer, 5-Aza-dC, promoter methylation

Colorectal cancer (CRC) is the second most commonly diagnosed cancer among females and the third among males, with an estimated 1,360,600 new cases diagnosed in 2012 and 693,900 deaths [1]. Even after surgery, chemotherapy or radiotherapy, the 5-year survival rate of patients with stage I, II, III or IV CRC is approximately $93,83,60$, or $8 \%$, respectively [2]. More effective therapeutic strategies are needed for CRC treatment.

Epigenetics is defined as heritable changes in gene expression without alteration of DNA sequences [3]. DNA methylation is one of the epigenetic modifications in mammalian cells [4]. CpG islands in the promoters of tumor-suppressor genes are usually unmethylated in normal cells and hypermethylation of $\mathrm{CpG}$ islands is commonly correlated with malignancies [4]. B-cell translocation gene 3 (BTG3) has been reported to be a tumor suppressor in cancers [5]. In addition, BTG3 is downregulated in diverse human cancers, including renal carcinoma, non-small cell lung cancer (NSCLC), cervical cancer, gastric cancer and esophageal adenocarcinoma [6-10], as well as in CRC [5]. The mechanism of BTG3 downregulation in tumor tissues may be associated with promoter hypermethylation $[6,11,12]$ and this hypothesis need to be further verified.

Cucurbitacins, isolated from plants of the families Cucurbitaceae and Cruciferae, are a group of tetracyclic triterpenoids possessing anti-inflammatory, anti-cancer and antidiabetic activities $[13,14]$. Cucurbitacin $\mathrm{B}(\mathrm{CuB})$, one of the most abundant member of cucurbitacins, has been reported to inhibit growth of numerous cancer cells [13]. Yar Saglam et al. have shown that treatment with $\mathrm{CuB}$ alone or in combination with gefitinib results in cell proliferation inhibition and apoptosis in CRC cells [15]. In addition, Shukla et al. have revealed that $\mathrm{CuB}$ inhibits NSCLC cell proliferation and tumorigenesis through modulating the expression of tumorrelated gene by epigenetic modifications [16]. However, whether $\mathrm{CuB}$ regulates $\mathrm{CRC}$ cell proliferation and apoptosis by inducing promoter demethylation of BTG3 remains unknown.

In the present study, we firstly examined BTG3 expression levels in CRC tissues and adjacent normal tissues and then tested the hypothesis whether $\mathrm{CuB}$ can induce expression of BTG3 in CRC by DNA demethylation. Next, we investigated 
whether $\mathrm{CuB}$ affects cell proliferation, cell cycle distribution and apoptosis via BTG3 in CRC.

\section{Materials and methods}

Tissue samples and cell culture. Tissue samples were obtained from patients at The First Affiliated Hospital of Jinzhou Medical University. Written consent was obtained from all patients and the protocols were approved by the Ethics Committee of Jinzhou Medical University. Tissue samples were immediately frozen in liquid nitrogen postsurgery and stored at $-80^{\circ} \mathrm{C}$.

SW480, Caco-2, HCT116, and Colo205 cells were purchased from Shanghai Zhong Qiao Xin Zhou Biotechnology Co.Ltd. (Shanghai, China). SW480 cells were cultured in L-15 medium (Zhong Qiao Xin Zhou Biotechnology) containing 10\% fetal bovine serum (FBS) (Biological Industries, Kibbutz Beit-Haemek, Israel). Caco-2 and Colo205 cells were maintained in RPMI 1640 medium (Hyclone, Logan, Utah, USA) supplemented with 10\% FBS. HCT116 cells were cultured in DMEM (Hyclone) with $10 \%$ FBS (Biological Industries). The cells were cultured at $37^{\circ} \mathrm{C}$ in a $5 \% \mathrm{CO}_{2}$ incubator.

Cell Counting Kit-8 (CCK-8) assay. Cells were seeded at 3000 cells/well into 96-well plates and then treated with increasing concentrations of $\mathrm{CuB}(0.1,0.5,1,5,10,25$, or $50 \mu \mathrm{M})$ (Selleck Chemicals, Houston, USA) for $48 \mathrm{~h}$. After discarding the cell supernatant, culture medium containing $10 \mu$ CCK-8 solutions (Sigma, St. Louis, USA) was added into each well and then the plates were placed at $37^{\circ} \mathrm{C}$ for $1 \mathrm{~h}$. The optical density at $450 \mathrm{~nm}$ was determined and the inhibition rate was calculated. The proper concentration of $\mathrm{CuB}$ was chosen for further studies.

For cell proliferation assay, the cells were transfected with siNC or siBTG3 (GenePharm, Shanghai, China) using Lipofectamine 2000 (Invitrogen, Carlsbad, USA) according to the manufacturer's instruction and then the siRNAtransfected cells were seeded into 96-well plates $24 \mathrm{~h}$ posttransfection. After being cultured for 0-72 h, the cells were incubated with CCK-8 solutions and then the optical density was measured at $450 \mathrm{~nm}$.

Cell transfection. Cells were seeded at $4 \times 10^{5}$ cells/plates into 6-well plates and cultured in a $5 \% \mathrm{CO}_{2}$ incubator. After $1 \mathrm{~h}$ of serum starvation, the cells were transfected with $100 \mathrm{pM}$ siNC or siBTG3 (GenePharm) using Lipofectamine 2000 (Invitrogen) according to the manufacturer's instructions. Twenty-four hours post-transfection, the cells were harvested and then treated with $5 \mu \mathrm{M} \mathrm{CuB}$ (Selleck Chemicals) for different time (0-72 h) prior to further studies.

Western blot. Total proteins were extracted from tissue samples or CRC cells using RIPA lysis buffer (Beyotime, Haimen, China). Bicinchoninic acid (BCA) Assay Kit (Beyotime) was used to measure protein concentration and an equal amounts of proteins $(40 \mu \mathrm{g})$ were separated by SDS-PAGE prior to transfer to PVDF membranes (Millipore,
Bedford, USA). Then, the membranes were blocked with nonfat milk (Yili Group, Hohhot, China) and then incubated with primary antibody against BTG3 (1:500 dilution) (Sangon, Shanghai, China), DNMT1 (1:1000 dilution), DNMT3a (1:1000 dilution), DNMT3b (1:500 dilution) (BIOSS, Beijing, China), Cyclin D1 (1:1000 dilution), Cyclin E1 (1:1000 dilution), cleaved caspase-3 (1:1000 dilution) and cleaved PARP (1:1000 dilution) (Cell Signaling Technology, Beverly, USA) at $4{ }^{\circ} \mathrm{C}$ overnight. Afterwards, the membranes were incubated with horseradish peroxidase (HRP)-labeled $\operatorname{IgG}\left(1: 5000\right.$ dilution) (Beyotime) at $37^{\circ} \mathrm{C}$ for $45 \mathrm{~min}$. Protein bands were detected with ECL reagent (Beyotime) and then quantified by Gel-Pro Analyzer (Media Cybernetics, Bethesda, USA).

Real-time PCR. Total RNAs were extracted from CRC cells using TRIpure reagent (BioTeke, Beijing, China), followed by determination of RNA concentration. Then, RNAs were reverse-transcribed into cDNAs and realtime PCR was performed using Exicycler ${ }^{\mathrm{TM}} 96$ Real-Time Quantitative Thermal Block (Bioneer, Daejeon, Korea). The primer sequences are as follows: BTG3-forward, 5'ATGAAATTGCTGCCGTTGTCT-3' and BTG3-reverse, 5'-GCCTGTCCTTTCGATGGTTTT-3'; $\beta$-actin-forward, 5'-CTTAGTTGCGTTACACCCTTTCTTG- 3 ' and $\beta$-actinreverse, 5'-CTGTCACCTTCACCGTTCCAGTTT-3'.

Bisulfite-sequencing PCR (BSP). Genomic DNA was isolated from CRC cells using Genomic DNA Extraction Kit (BioTeke Corporation, Beijing, China) and then subjected to bisulfite conversion using EZ DNA Methylation-Gold Kit (ZYMO Research, Tustin, USA) according to the manufacturer's instructions. The bisulfite-converted genomic DNA was subjected to PCR. PCR products were separated by $1.5 \%$ agarose gel electrophoresis and purified using DNA Gel Extraction Kit (BioTeke Corporation). The sequences of primers used are as follows: BTG3-forward, 5'-GTTTAAAATATAGTAGGG-3' and BTG3-reverse, 5'-CCCTACCCTAAACCTAAC-3'. The purified PCR products were cloned into pGEM-T Easy Vector (Promega Corporation, Madison, USA) and five clones were randomly chosen for bisulfite sequencing.

Immunofluorescence. The slides were fixed in $4 \%$ paraformaldehyde, washed three times with PBS and treated with $0.1 \%$ Triton X-100 for $30 \mathrm{~min}$. After being washed, the slides were blocked with goat serum and incubated with primary antibody against Ki67 (1:100 dilution) (Proteintech, Wuhan, China) at $4^{\circ} \mathrm{C}$ overnight. Afterwards, the slides were incubated with Cy3-labelled secondary antibody (1:200 dilution) (Beyotime) at room temperature for $1 \mathrm{~h}$. Nuclei were counterstained with DAPI (Beyotime) and subsequently the slides were photographed under a fluorescent microscope (Olympus, Tokyo, Japan).

Cell cycle distribution. Cells were harvested by centrifugation, washed twice with PBS and fixed in 70\% ethanol at $4^{\circ} \mathrm{C}$ for $12 \mathrm{~h}$. The fixed cells were resuspended and stained with $25 \mu \mathrm{l}$ Propidium Iodide (PI) (Beyotime) and $10 \mu \mathrm{l}$ RNase 
A

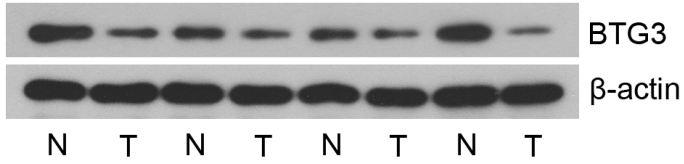

B

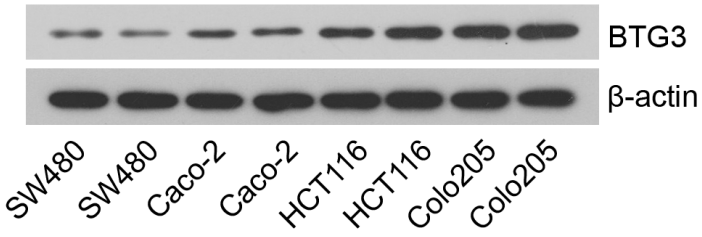

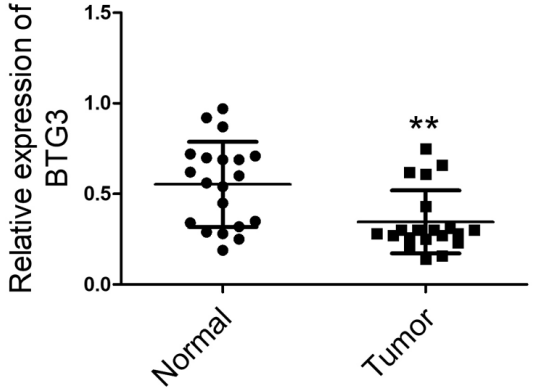

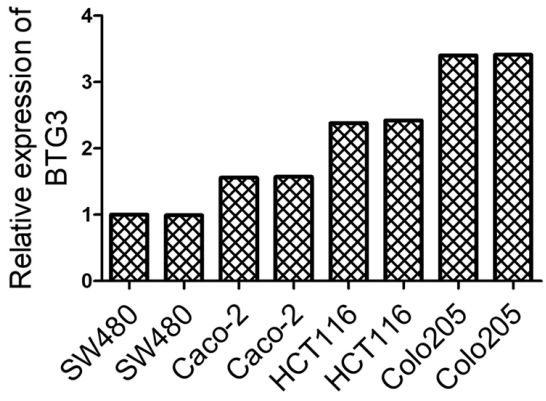

Figure 1. BTG3 expression in colorectal cancer (CRC) tissues and four CRC cell lines. A) The levels of BTG3 in 20 pairs of CRC tissues (T) and adjacent normal tissues (N) were determined by western blot. B) BTG3 expression levels in four CRC cell lines (SW480, Caco-2, HCT116 and Colo205) were examined by western blot. $\beta$-actin was used as internal control. Results are expressed as mean \pm SD. ${ }^{* *}$ indicates $\mathbf{p}<0.01$.

A (Beyotime) at $37^{\circ} \mathrm{C}$ for $30 \mathrm{~min}$ in the dark. Cell cycle distribution was analyzed by flow cytometry.

Cell apoptosis. Cell apoptosis was examined using Annexin V-FITC Apoptosis Detection Kit (Beyotime) according to the manufacturer's instructions. Briefly, the cells were washed with PBS and resuspended in binding buffer. Then, $5 \mu \mathrm{l}$ Annexin V-FITC and $10 \mu \mathrm{l}$ PI were added to stain the cells for $15 \mathrm{~min}$ in the dark before flow cytometric analysis.

Statistical analysis. Data are expressed as mean \pm SD. One-way ANOVA followed by Tukey post-hoc test or Student's $t$ test was used for statistical analysis. A $\mathrm{p}<0.05$ was considered to be statistically significant.

\section{Results}

BTG3 is downregulated in human CRC tissues. To determine BTG3 expression in 20 paired of human CRC tissues and adjacent normal colorectal tissues, western blot was performed. The results showed that BTG3 is markedly downregulated in CRC tissues compared with adjacent normal tissues (Figure 1A).

Selection of cell lines and $\mathrm{CuB}$ concentration. BTG3 expression levels in four CRC cell lines were determined by western blot. We found that SW480 and Caco-2 cells expressed lower levels of BTG3 than HCT116 and Colo205 cells (Figure 1B). Thus, SW480 and Caco-2 cells were chosen for further studies.

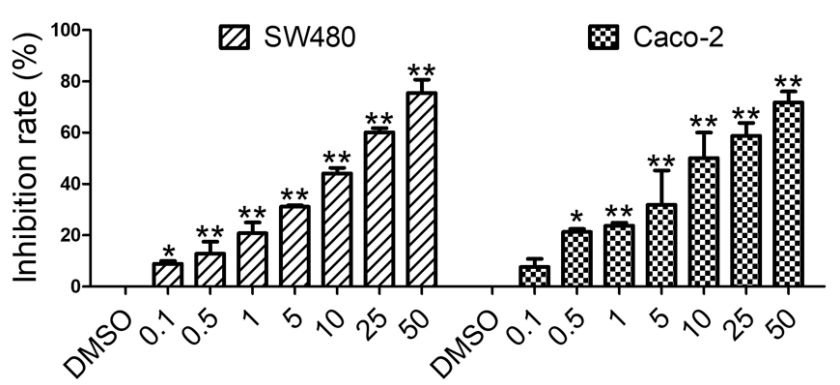

Figure 2. Selection of proper CuB concentration. SW480 and Caco-2 cells were incubated with increasing doses of $\mathrm{CuB}(0.1,0.5,1,5,10,25$, and $50 \mu \mathrm{M})$ for $48 \mathrm{~h}$. Inhibition rate was measured by CCK-8 assay. Results are expressed as mean $\pm \mathrm{SD}$. ${ }^{*}$ indicates $\mathbf{p}<0.05$ and ${ }^{*}$ indicates $\mathbf{p}<0.01$ compared with the DMSO group.

CCK-8 assay was performed to choose the proper concentration of $\mathrm{CuB}$. The results showed that $\mathrm{CuB}$ significantly reduced cell viability in a dose-dependent manner in both SW480 and Caco-2 cells (Figure 2). In the present study, $5 \mu \mathrm{M}$ of $\mathrm{CuB}$ was chosen.

CuB reactivates BTG3 by promoter demethylation of BTG3 in CRC cells. To investigate the effect of $\mathrm{CuB}$ on the expression levels of BTG3, CRC cells were incubated with $\mathrm{CuB}$ for $48 \mathrm{~h}$ and then subjected to real-time PCR and western blot. 5-Aza-dC was used as a positive control. The results showed that $\mathrm{CuB}$ and 5-Aza-dC significantly elevated the mRNA and protein levels of BTG3 in both SW480 and 
Caco-2 cells compared with the vehicle control (Figure 3A). Next, we investigated whether this elevation of BTG3 expression is due to the promoter demethylation in CRC cells. The results showed that BTG3 promoter was hypermethylated in the vehicle (DMSO)-treated cells (Figure 3B), as determined by bisulfite-sequencing PCR (BSP). CuB or 5-Aza-dC treatment significantly induced promoter demethylation of BTG3 in both SW480 and Caco-2 cells. We then determined the levels of three key DNA methyltransferases by western blot. The results showed that the levels of DNMT1, DNMT3a and DNMT3b were markedly reduced in CuB- or 5-Aza-dC- treated cells compared with those in the vehicle control cells (Figure 4).

CuB inhibits cell proliferation in CRC cells in vitro. To explore whether BTG3 is involved in CuB-induced modulation of CRC progression, BTG3 was knocked down in CRC cells and then incubated with $5 \mu \mathrm{M} \mathrm{CuB}$. We found that $\mathrm{CuB}$ treatment led to elevation of BTG3 expression at both mRNA and protein levels. However, siBTG3 transfection attenuated CuB-induced increases in BTG3 levels (Figure 5A). Cell proliferation was examined by CCK-8 assay. The results showed that $\mathrm{CuB}$ significantly inhibited cell proliferation in

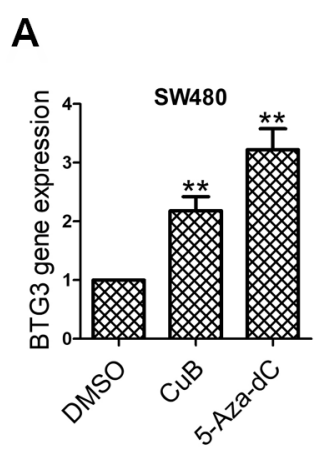

B

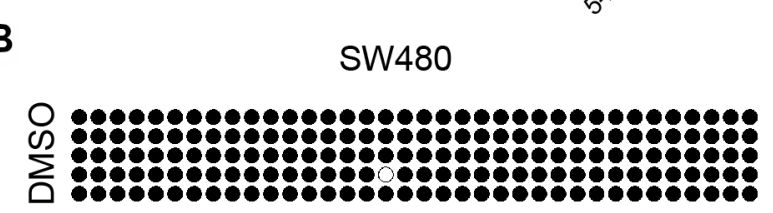
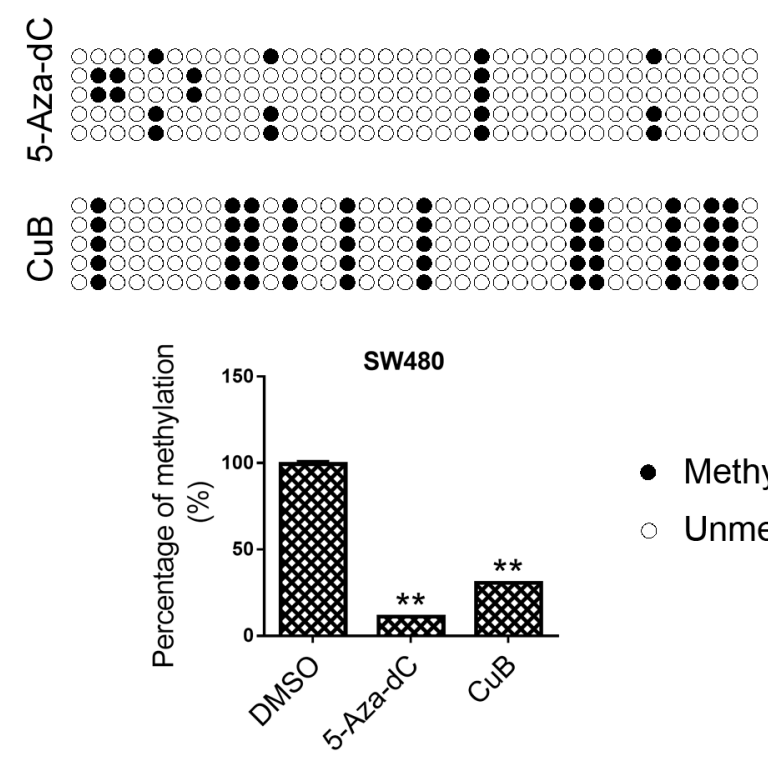

BTG3
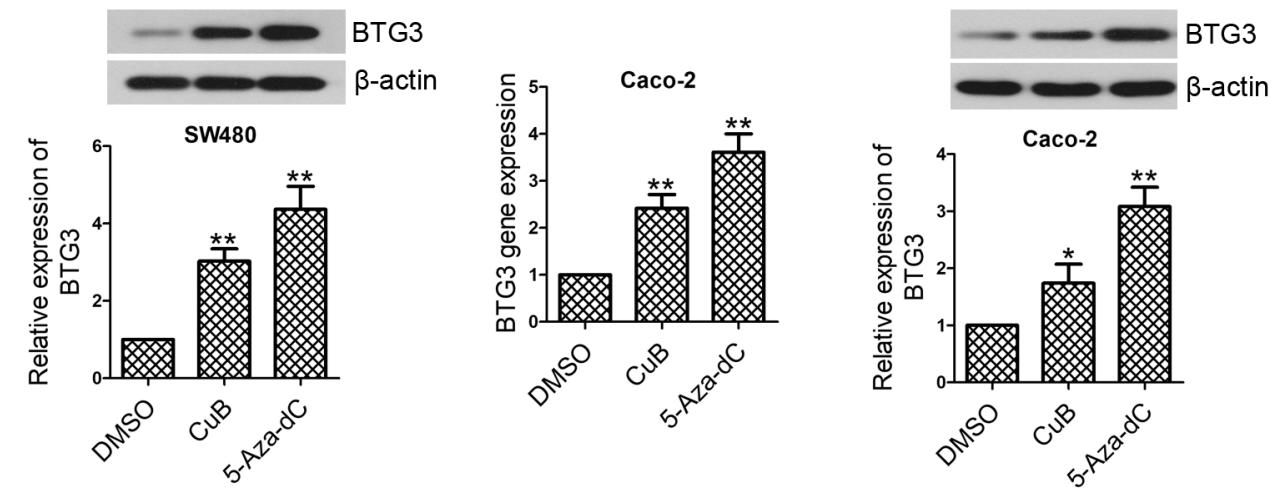

Caco-2
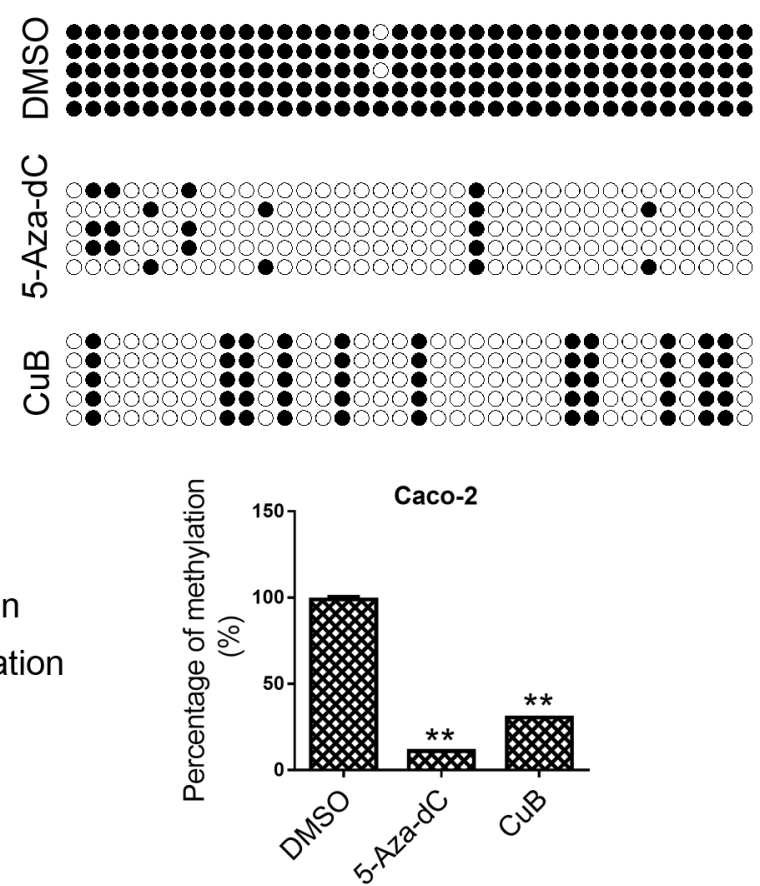

Figure 3. Effect of $\mathrm{CuB}$ and 5-Aza-dC on the expression and methylation status of BTG3. The cells were treated with $\mathrm{CuB}(5 \mu \mathrm{M})$ or $5-\mathrm{Aza}-\mathrm{dC}(5 \mu \mathrm{M})$ and then subjected to further analyses. A) BTG3 expression was determined by real-time PCR and western blot. $\beta$-actin was used as internal control. B) Bisulfite-sequencing PCR (BSP) analysis of BTG3 promoter in SW480 and Caco-2 cells. Results are expressed as mean \pm SD. ${ }^{\star}$ indicates $p<0.05$ and ${ }^{* *}$ indicates $\mathrm{p}<0.01$ compared with the DMSO group. 

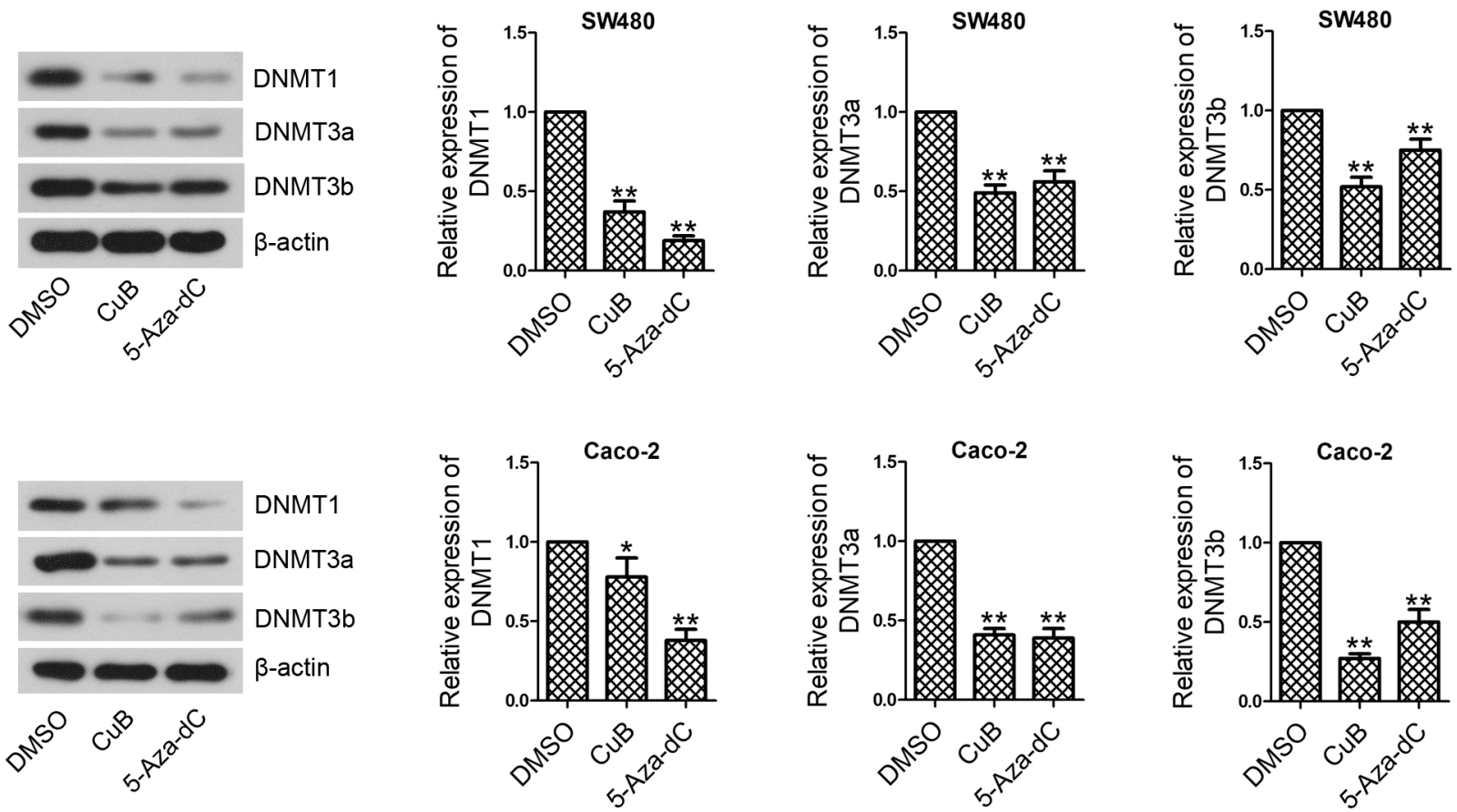

Figure 4. Effect of CuB and 5-Aza-dC on the levels of DNA methyltransferases. After incubation with CuB or 5-Aza-dC, the levels of DNMT1, DNMT3a and DNMT3b were determined by western blot. $\beta$-actin was used as internal control. Results are expressed as mean \pm SD. ${ }^{\star}$ indicates p<0.05 and ${ }^{\star *}$ indicates $\mathrm{p}<0.01$ compared with the DMSO group.

both SW480 and Caco-2 cells in vitro, which was reversed by BTG3 knockdown (Figure 5B). Ki67 expression was measured by immunofluorescence. We found that $\mathrm{CuB}$ treatment decreased Ki67 expression in both SW480 and Caco-2 cells; whereas, BTG3 knockdown blocked the effects of $\mathrm{CuB}$ (Figure 5C).

CuB arrests the cell cycle at G1 phase in CRC cells in vitro. Cell cycle distribution was analyzed by flow cytometry. The results showed that $\mathrm{CuB}$ caused cell cycle arrest at G1 phase in both SW480 and Caco-2 cells, which was reversed by siBTG3 transfection (Figure 6A). Cyclin D1 and Cyclin E1 levels were determined by western blot. The results showed that $\mathrm{CuB}$ incubation significantly decreased Cyclin D1 and Cyclin E1 levels in both SW480 and Caco-2 cells. Knockdown of BTG3 restored the levels of Cyclin D1 and Cyclin E1 even in the presence of $\mathrm{CuB}$ (Figure 6B).

$\mathrm{CuB}$ induces cell apoptosis in CRC cells in vitro. Cell apoptosis was analyzed by flow cytometry. The results showed that $\mathrm{CuB}$ significantly induced cell apoptosis in both SW480 and Caco-2 cells in vitro. BTG3 knockdown inhibited the promoting effect of $\mathrm{CuB}$ on cell apoptosis (Figure 7A). Next, the levels of cleaved capase- 3 and cleaved PARP were determined by western blot. We found that SW480 and Caco-2 cells treated with $\mathrm{CuB}$ expressed higher levels of cleaved capase- 3 and cleaved PARP compared with the vehicle control cells. BTG3 knockdown reversed the elevated levels of cleaved capase- 3 and cleaved PARP induced by $\mathrm{CuB}$ treatment (Figure 7B).

\section{Discussion}

DNA methylation is an important mechanism for gene silencing, including tumor suppressor genes, inhibitors of oncogenes, DNA repair genes and cell cycle regulators [17, 18]. A previous study has revealed that $\mathrm{CuB}$ suppresses cell proliferation and induces cell apoptosis in NSCLC by epigenetically regulating the expression of tumor-related genes [16]. This is the first report to investigate whether $\mathrm{CuB}$ reactivates BTG3 through DNA demethylation and then affects cell proliferation, cell cycle distribution and cell apoptosis in CRC.

In the present study, we demonstrated that BTG was significantly downregulated in 20 paired of human CRC tissues compared with adjacent normal tissues, which is consistent with previous observations $[5,9]$. In addition, aberrant hypermethylation status of BTG3 promoter has been reported in several human cancers $[6,11,19]$. Therefore, we hypothesized that promoter methylation in the $\mathrm{CpG}$ island of BTG3 may contribute to BTG3 silencing in CRC tissues. Although there are other mechanisms that mediate BTG3 suppression, e.g. miR-20a-5p and miR-106b-5p [7, $8]$, promoter methylation is still the frequent mechanism of tumor suppressor gene (TSG) silencing in cancers. 5-Aza$\mathrm{dC}$, an inhibitor of DNA methyltransferase [20], was used as a positive control in our study. We found that both $\mathrm{CuB}$ and 5-Aza-dC increased BTG3 expression in both CRC cells, as evidenced by real-time PCR and western blot. The methyla- 


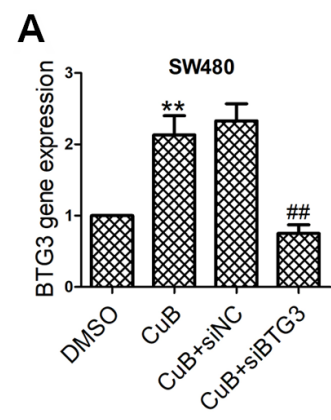

B
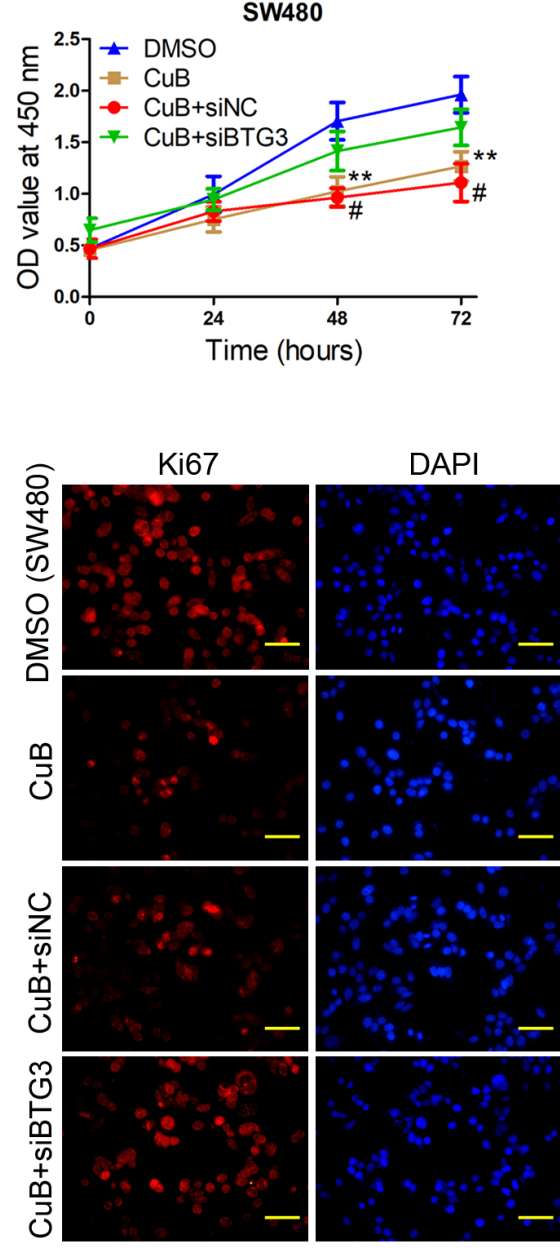
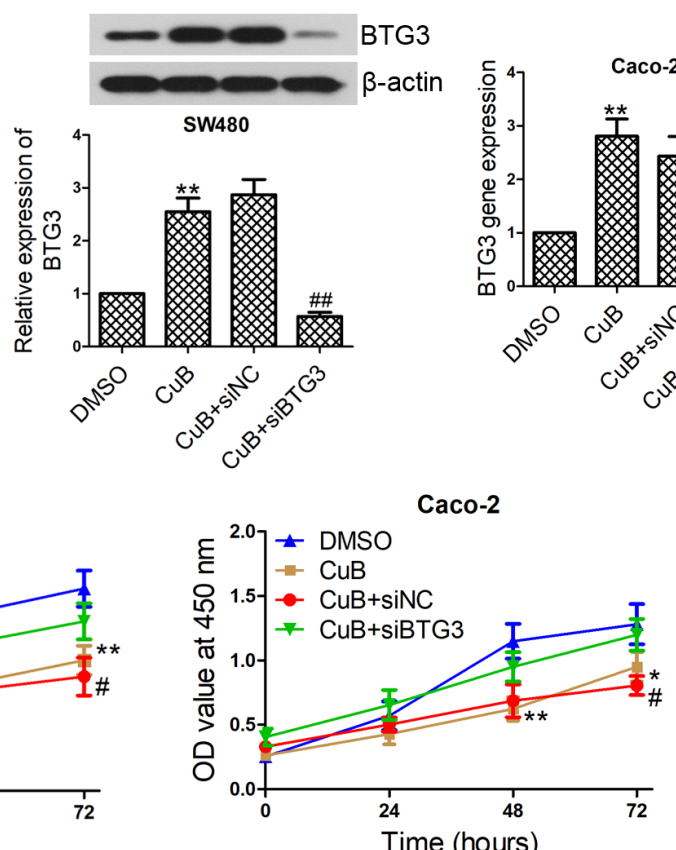
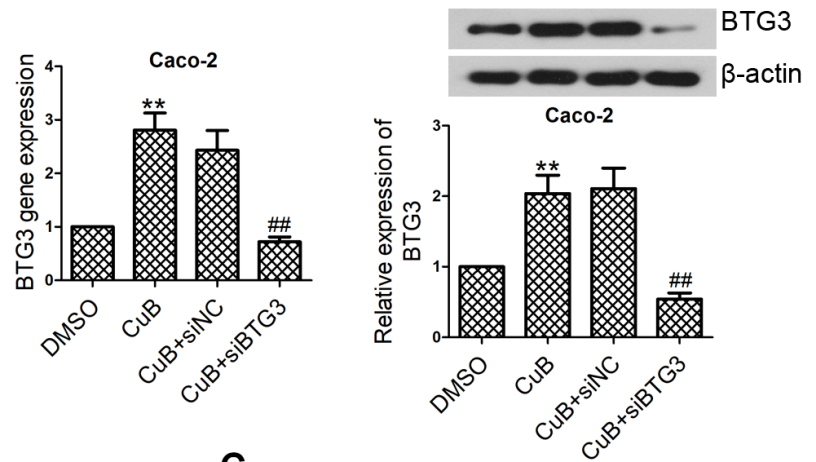

C
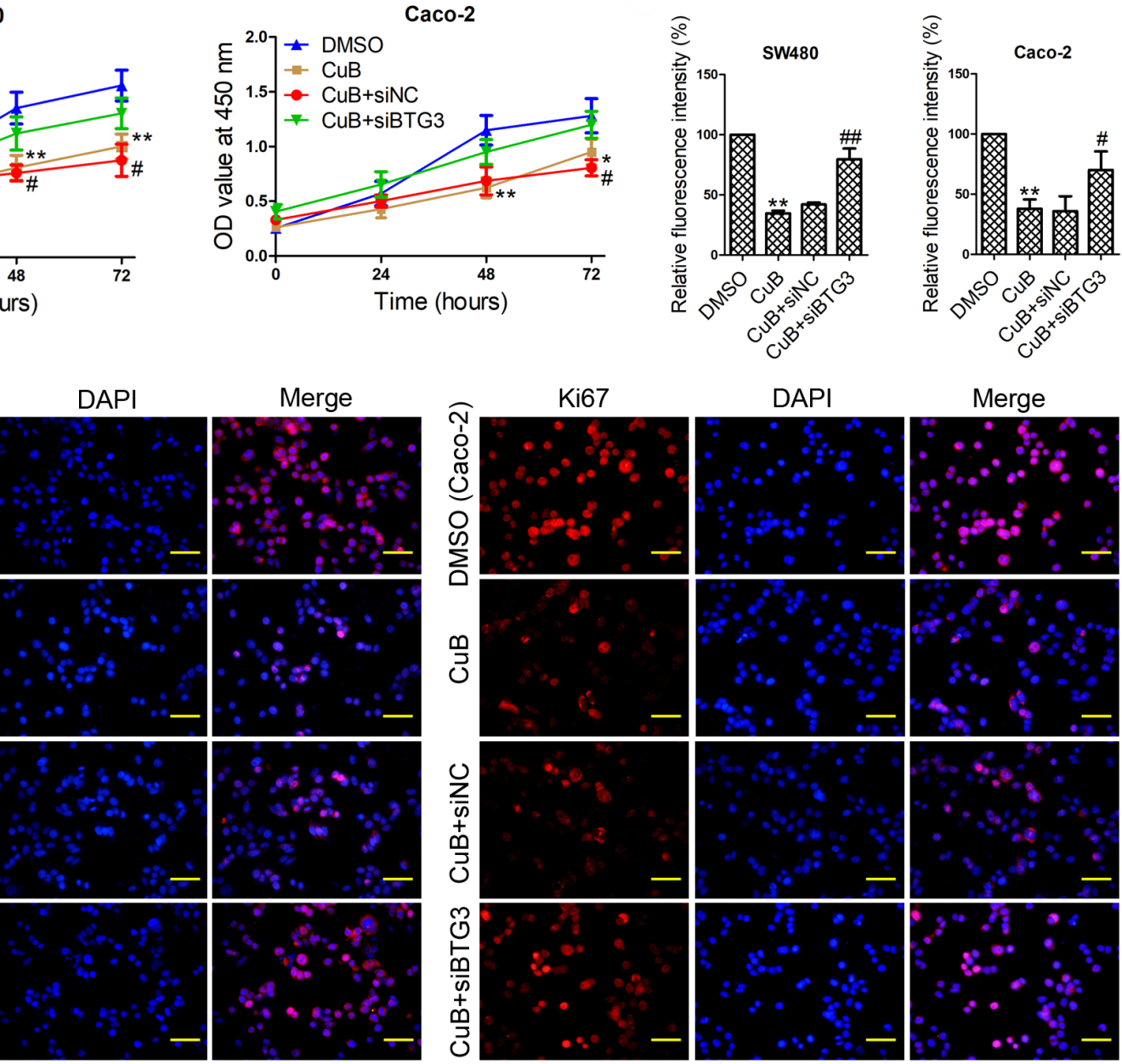

Figure 5. Effect of $\mathrm{CuB}$ on cell proliferation in CRC cells in vitro. SW480 and Caco-2 cells were transfected with siBTG3 or siNC and then incubated with $5 \mu \mathrm{M} \mathrm{CuB}$ for different time $24 \mathrm{~h}$ post-transfection. A) After $48 \mathrm{~h}$ of incubation with CuB, real-time PCR and western blot were performed to determine BTG3 expression. $\beta$-actin was used as internal control. B) Cell proliferation was determined by CCK-8 assay (0, 24,48 , and 72 h). C) Ki67 expression was analyzed by immunofluorescence. Scale bar represents $50 \mu \mathrm{m}$. Results are expressed as mean $\pm \mathrm{SD}$. ${ }^{\star}$ indicates $\mathrm{p}<0.05$ and ${ }^{\star *}$ indicates $\mathrm{p}<0.01$ compared to the DMSO group. \# indicates $\mathrm{p}<0.05$ and \#\# indicates $\mathrm{p}<0.01$ compared with the CuB + siNC group.

tion status of BTG3 promoter region was then determined by bisulfite-sequencing PCR (BSP). The results showed that $\mathrm{CuB}$ and 5 -Aza-dC induced demethylation of BTG3 promoter in both SW480 and Caco-2 cells. In mammals, DNA methylation is catalyzed by three key enzymes, namely
DNMT1, DNMT3a and DNMT3b [17]. Decreased levels of DNMT1, DNMT3a and DNMT3b were observed in CuB- or 5-Aza-dC-treated cells compared with the vehicle control. The results suggest that $\mathrm{CuB}$ may reactivate BTG3 expression by promoter demethylation. 

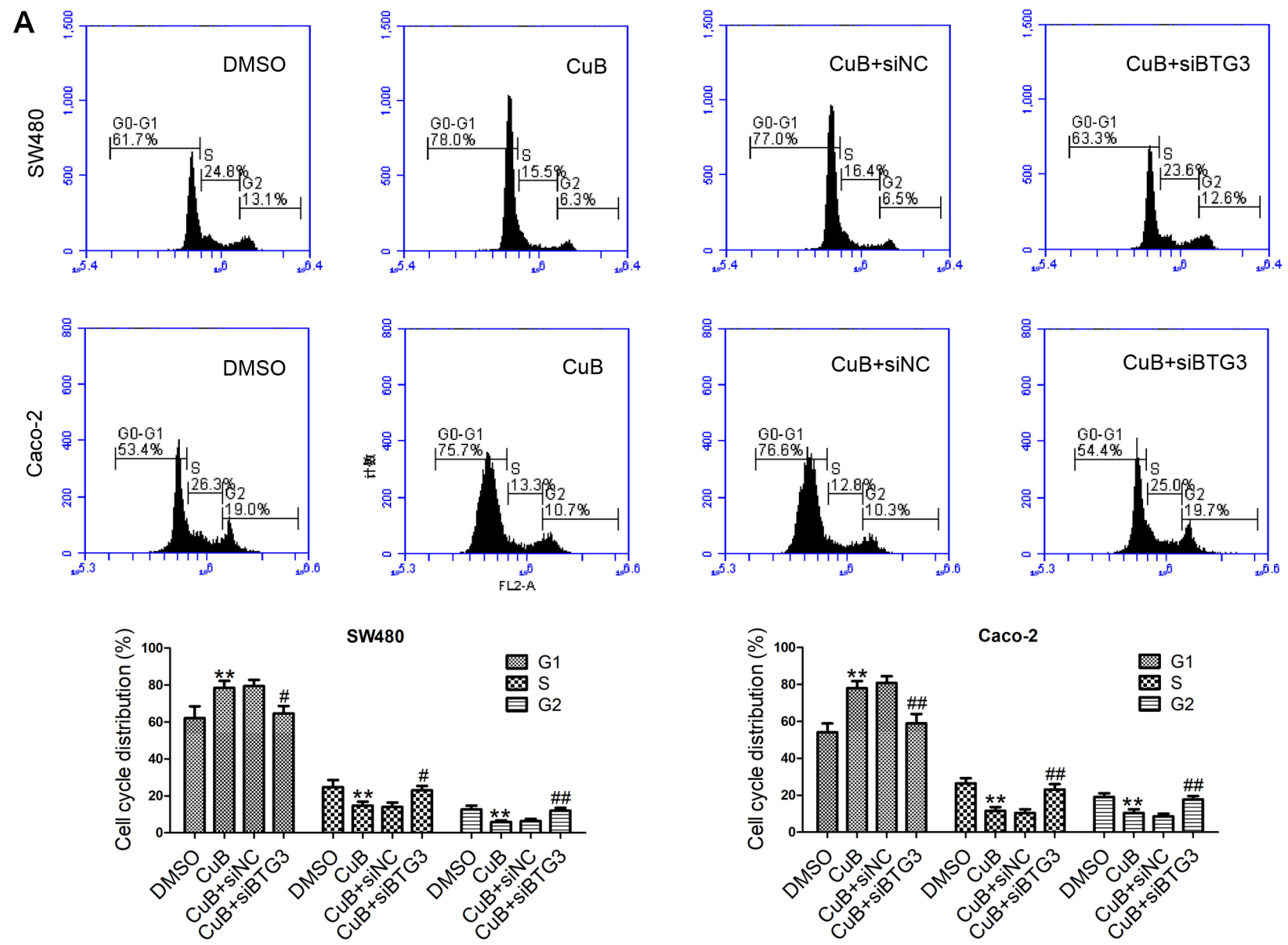

B
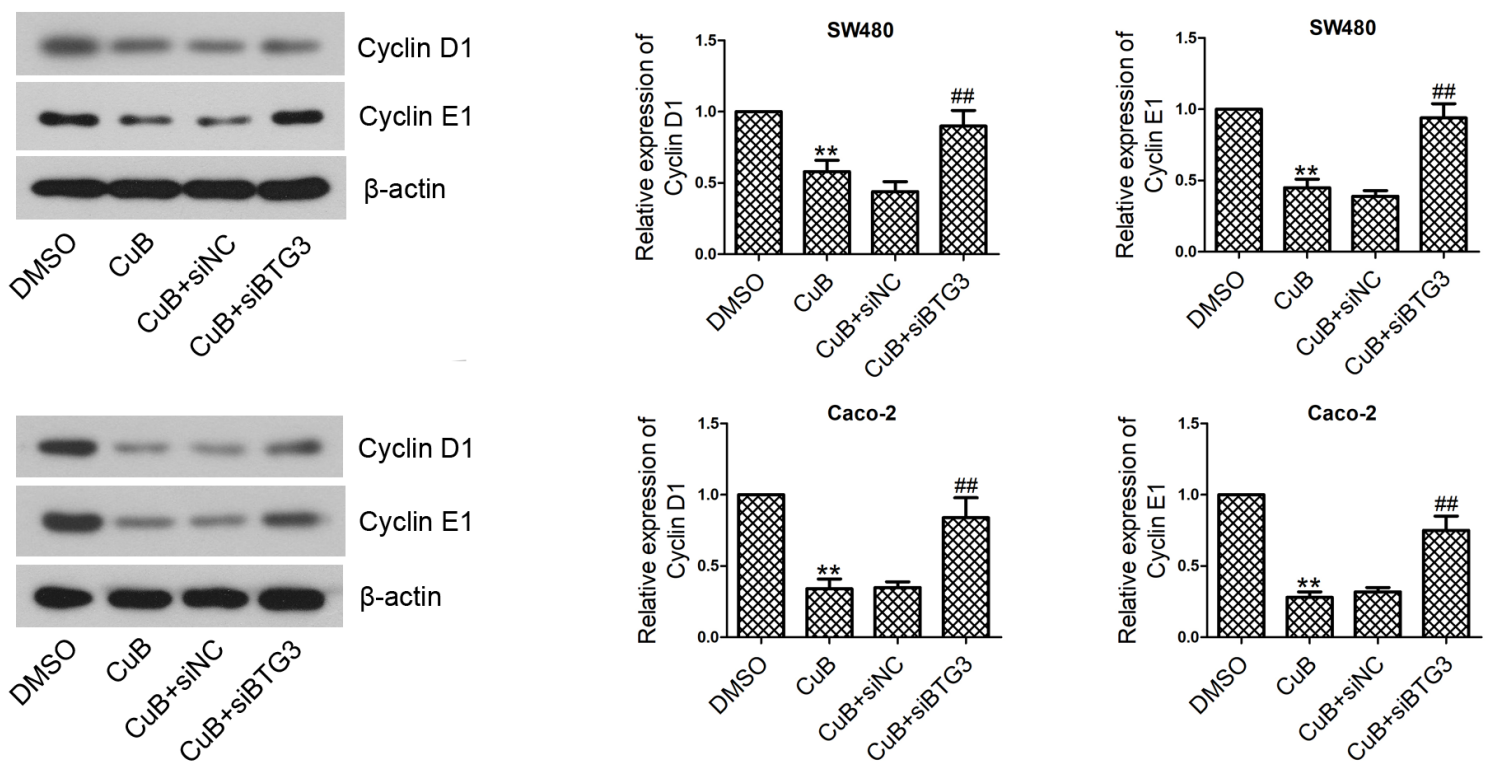

Figure 6. Effect of CuB on cell cycle distribution in CRC cells in vitro. SW480 and Caco-2 cells transfected with siBTG3 or siNC were treated with $5 \mu$ M $\mathrm{CuB}$ for $48 \mathrm{~h}$ prior to further analyses. A) Cell cycle distribution was analyzed by flow cytometry. B) The levels of Cyclin D1 and Cyclin E1 were determined by western blot. $\beta$-actin was used as internal control. Results are expressed as mean $\pm \mathrm{SD}$. ${ }^{\star}$ indicates $\mathrm{p}<0.05$ and ${ }^{\star *}$ indicates $\mathrm{p}<0.01$ compared to the DMSO group. \# indicates $\mathrm{p}<0.05$ and \#\# indicates $\mathrm{p}<0.01$ compared with the $\mathrm{CuB}+\operatorname{siNC}$ group. 

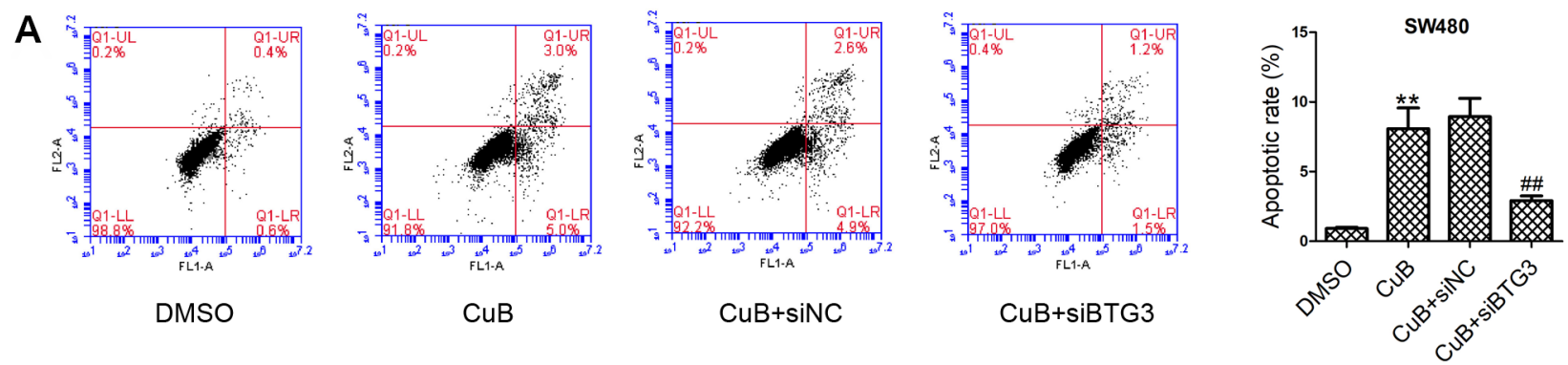

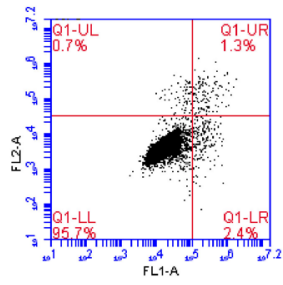

DMSO
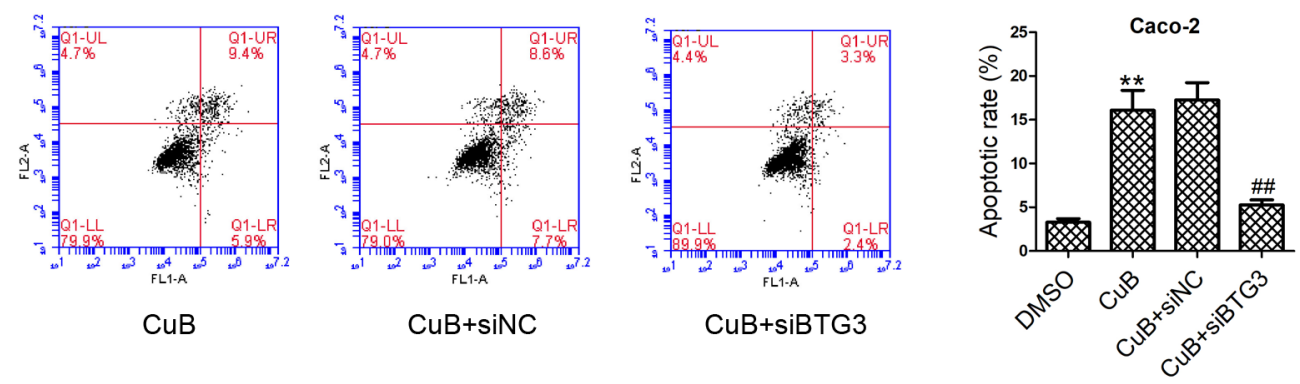

B
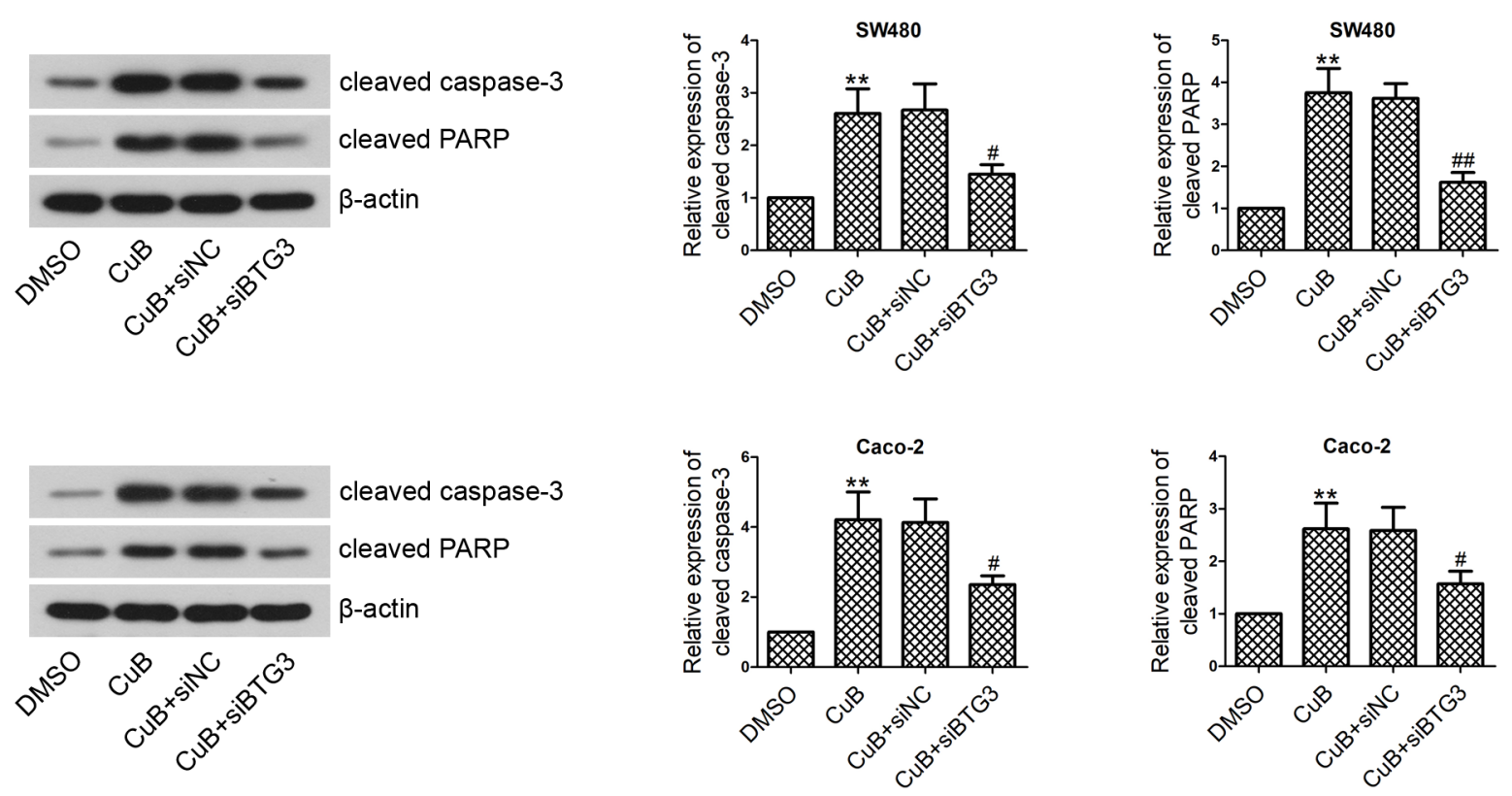

Figure 7. Effect of $\mathrm{CuB}$ on cell apoptosis in CRC cells in vitro. The siRNA-transfected cells were incubated with CuB for 24 h and then subjected to further analyses. A) Flow cytometric analysis of cell apoptosis. B) The levels of cleaved caspase-3 and cleaved PARP were determined by western blot. $\beta$-actin was used as internal control. Results are expressed as mean \pm SD. ${ }^{\star}$ indicates $\mathbf{p}<0.05$ and ${ }^{\star \star}$ indicates $\mathbf{p}<0.01$ compared to the DMSO group. \# indicates $\mathrm{p}<0.05$ and \#\# indicates $\mathrm{p}<0.01$ compared with the $\mathrm{CuB}+\mathrm{siNC}$ group.

Cell proliferation plays an important role in cancer development and progression [21]. Increasing evidences have reported that $\mathrm{CuB}$ treatment suppresses cell proliferation in various cancers, including lung cancer, breast cancer, glioblastoma and cutaneous squamous cell carcinoma [14, 22-24]. Consistently, treatment with CuB significantly inhibited proliferation of SW480 and Caco-2 cells in vitro as determined by CCK- 8 assay. Ki67, one of the widely used markers of cell proliferation, is strongly expressed in proliferating cells, but not in non-dividing cells $[25,26]$. Ki67 expression was analyzed by immunofluorescence to assess cell proliferation. The results showed that $\mathrm{CuB}$ treatment significantly decreased Ki67 expression levels in both SW480 and Caco-2 cells compared with the vehicle control. 
The data indicated that $\mathrm{CuB}$ has an anti-proliferative effect on CRC cells in vitro.

Cancer is characterized by uncontrolled cell proliferation caused by abnormal activation of cell cycle-related proteins [27]. Cyclin D1 regulates G1/S-phase transition through forming complex with Cdk4 and Cdk6 [28, 29]. Cyclin E1, expressed in late G1 and S phase of the cell cycle, also promotes cell cycle progression from G1 phase into $S$ phase [30]. Then, we evaluated whether cell proliferation inhibition induced by $\mathrm{CuB}$ is due to aberrant expression of cell cycle-related proteins. The results showed that treatment with $\mathrm{CuB}$ led to decreases in Cyclin D1 and Cyclin $\mathrm{E} 1$ levels in $\mathrm{CRC}$ cells, suggesting that $\mathrm{CuB}$ may inhibit cell proliferation via regulation of cell cycle progression.

Apoptosis (also called programmed cell death), an important form of cell death, has been reported to be dysregulated in human cancers [31]. In the present study, flow cytometric analysis revealed that $\mathrm{CuB}$ strongly induced SW480 and Caco-2 cell apoptosis in vitro and the pro-apoptotic effect of $\mathrm{CuB}$ was previously observed in other cancer cells $[13,32,33]$. Caspases are a family of cysteine proteases functioning in cell apoptosis [34]. Both extrinsic and intrinsic apoptosis pathways can activate the executioner caspase-3, followed by cleavage of downstream substrates to amplify the apoptotic signal [35]. Poly(ADPribose) polymerase (PARP) is a major substrate of caspase- 3 and can be cleaved into $89-$ and $24-\mathrm{kDa}$ fragments by activated caspase- 3 during apoptosis [36]. We found that $\mathrm{CuB}$ significantly increased cleaved caspase- 3 and cleaved PARP in both SW480 and Caco-2 cells, suggesting that $\mathrm{CuB}$ may induce $\mathrm{CRC}$ cell apoptosis through regulating the activation of caspase- 3 and PARP.

Our previous study and other reports have demonstrated that BTG3 overexpression suppresses cell proliferation and promotes apoptosis in CRC, epithelial ovarian cancer and esophageal adenocarcinoma [37-40]. These evidences demonstrate that BTG3 exerts anti-proliferative and pro-apoptotic effects in CRC and other human cancers. To further verify the involvement of BTG3 in CuB-induced proliferation inhibition and apoptosis induction, both cell lines were transfected with siBTG3 or siNC and then treated with $\mathrm{CuB}$ prior to analyses. The results showed that BTG3 knockdown rescued the effects of $\mathrm{CuB}$ on cell proliferation, cell cycle distribution and cell apoptosis, suggesting the involvement of BTG3.

In conclusion, promoter methylation might contribute to epigenetic silencing of BTG3 in CRC. Furthermore, $\mathrm{CuB}$, which possessed similar effects to 5 -Aza-dC, inhibited cell proliferation, arrested the cell cycle at G1 phase and induced cell apoptosis through promoter demethylation of BTG3 in CRC.

Acknowledgements: This study was supported by a grant from the Natural Science Foundation of Liaoning Province (No. 20170540360).

\section{References}

[1] TORRE LA, BRAY F, SIEGEL RL, FERLAY J, LORTETTIEULENT J et al. Global cancer statistics, 2012. CA Cancer J Clin 2015; 65: 87-108. https://doi.org/10.3322/ caac. 21262

[2] HOU J, ZHANG Y, ZHU Z. Gene heterogeneity in metastasis of colorectal cancer to the lung. Semin Cell Dev Biol 2017; 64: 58-64. https://doi.org/10.1016/j.semcdb.2016.08.034

[3] YEN CY, HUANG HW, SHU CW, HOU MF, YUAN SS et al. DNA methylation, histone acetylation and methylation of epigenetic modifications as a therapeutic approach for cancers. Cancer Lett 2016; 373: 185-192. https://doi. org/10.1016/j.canlet.2016.01.036

[4] ABDEL-HAFIZ HA, HORWITZ KB. Role of epigenetic modifications in luminal breast cancer. Epigenomics2015; 7 : 847-862. https://doi.org/10.2217/epi.15.10

[5] LV C, WANG H, TONG Y, YIN H, WANG D et al. The function of BTG3 in colorectal cancer cells and its possible signaling pathway. J Cancer Res Clin Oncol 2018; 144: 295-308. https://doi.org/10.1007/s00432-017-2561-9

[6] MAJID S, DAR AA, AHMAD AE, HIRATA H, KAWAKAMI $\mathrm{K}$ et al. BTG3 tumor suppressor gene promoter demethylation, histone modification and cell cycle arrest by genistein in renal cancer. Carcinogenesis 2009; 30: 662-670. https:// doi.org/10.1093/carcin/bgp042

[7] WEI K, PAN C, YAO G, LIU B, MA T et al. MiR-106b-5p Promotes Proliferation and Inhibits Apoptosis by Regulating BTG3 in Non-Small Cell Lung Cancer. Cell Physiol Biochem 2017; 44: 1545-1558. https://doi.org/10.1159/000485650

[8] XIONG Y, SUN F, DONG P, WATARI H, YUE J et al. iASPP induces EMT and cisplatin resistance in human cervical cancer through miR-20a-FBXL5/BTG3 signaling. J Exp Clin Cancer Res 2017; 36: 48. https://doi.org/10.1186/s13046017-0520-6

[9] REN XL, ZHU XH, LI XM, LI YL, WANG JM et al. Downregulation of BTG3 promotes cell proliferation, migration and invasion and predicts survival in gastric cancer. J Cancer Res Clin Oncol 2015; 141: 397-405. https://doi.org/10.1007/ s00432-014-1826-9

[10] DU Y, LIU P, ZANG W, WANG Y, CHEN X et al. BTG3 upregulation induces cell apoptosis and suppresses invasion in esophageal adenocarcinoma. Mol Cell Biochem 2015; 404: 31-38. https://doi.org/10.1007/s11010-015-2363-9

[11] LV Z, ZOU H, PENG K, WANG J, DING Y et al. The suppressive role and aberrent promoter methylation of BTG3 in the progression of hepatocellular carcinoma. PLoS One 2013; 8: e77473. https://doi.org/10.1371/journal.pone.0077473

[12] MAJID S, DAR AA, SHAHRYARI V, HIRATA H, AHMAD $A$ et al. Genistein reverses hypermethylation and induces active histone modifications in tumor suppressor gene B-Cell translocation gene 3 in prostate cancer. Cancer 2010; 116: 66-76. https://doi.org/10.1002/cncr.24662

[13] QIN S, LI J, SI Y, HE Z, ZHANG T et al. Cucurbitacin B induces inhibitory effects via CIP2A/PP2A/Akt pathway in glioblastoma multiforme. Mol Carcinog 2018; 57: 687-699. https://doi.org/10.1002/mc.22789 
[14] KHAN N, JAJEH F, KHAN MI, MUKHTAR E, SHABANA $\mathrm{SM}$ et al. Sestrin-3 modulation is essential for therapeutic efficacy of cucurbitacin B in lung cancer cells. Carcinogenesis 2017; 38: 184-195. https://doi.org/10.1093/carcin/bgw124

[15] YAR SAGLAM AS, ALP E, ELMAZOGLU Z, MENEVSE S. Treatment with cucurbitacin $B$ alone and in combination with gefitinib induces cell cycle inhibition and apoptosis via EGFR and JAK/STAT pathway in human colorectal cancer cell lines. Hum Exp Toxicol 2016; 35: 526-543. https://doi. org/10.1177/0960327115595686

[16] SHUKLA S, KHAN S, KUMAR S, SINHA S, FARHAN M et al. Cucurbitacin B Alters the Expression of Tumor-Related Genes by Epigenetic Modifications in NSCLC and Inhibits NNK-Induced Lung Tumorigenesis. Cancer Prev Res (Phila) 2015; 8: 552-562. https://doi.org/10.1158/1940-6207.CAPR-14-0286

[17] TABY R, ISSA JP. Cancer epigenetics. CA Cancer J Clin 2010; 60: 376-392. https://doi.org/10.3322/caac.20085

[18] ESTELLER M. Epigenetics in cancer. N Engl J Med 2008; 358: 1148-1159. https://doi.org/10.1056/NEJMra072067

[19] YUJ,ZHANGY,QIZ,KURTYCZD, VACANOGetal. Methylation-mediated downregulation of the B-cell translocation gene 3 (BTG3) in breast cancer cells. Gene Expr 2008; 14: 173-182.

[20] SHENG W, ZHANG ZC, SHI DY, WANG BC, WU Q et al. Epigenetic silencing of SFRP5 promotes the metastasis and invasion of chondrosarcoma by expression inhibition and Wnt signaling pathway activation. Chem Biol Interact 2018; 296: 1-8. https://doi.org/10.1016/j.cbi.2018.08.020

[21] FEITELSON MA, ARZUMANYAN A, KULATHINAL RJ, BLAIN SW, HOLCOMBE RF et al. Sustained proliferation in cancer: Mechanisms and novel therapeutic targets. Semin Cancer Biol 2015; 35 Suppl: S25-S54. https://doi. org/10.1016/j.semcancer.2015.02.006

[22] DUANGMANO S, SAE-LIM P, SUKSAMRARN A, DOMANN FE, PATMASIRIWAT P. Cucurbitacin B inhibits human breast cancer cell proliferation through disruption of microtubule polymerization and nucleophosmin/B23 translocation. BMC Complement Altern Med 2012; 12: 185. https://doi.org/10.1186/1472-6882-12-185

[23] TOUIHRI-BARAKATI I, KALLECH-ZIRI O, AYADI W, KOVACIC H, HANCHI B et al. Cucurbitacin B purified from Ecballium elaterium (L.) A. Rich from Tunisia inhibits alpha5beta1 integrin-mediated adhesion, migration, proliferation of human glioblastoma cell line and angiogenesis. Eur J Pharmacol 2017; 797: 153-161. https://doi.org/10.1016/j. ejphar.2017.01.006

[24] CHEN W, LEITER A, YIN D, MEIRING M, LOUW VJ et al. Cucurbitacin B inhibits growth, arrests the cell cycle, and potentiates antiproliferative efficacy of cisplatin in cutaneous squamous cell carcinoma cell lines. Int J Oncol 2010; 37: 737-743. https://doi.org/10.3892/ijo_00000723

[25] JURIKOVA M, DANIHEL L, POLAK S, VARGA I. Ki67, PCNA, and MCM proteins: Markers of proliferation in the diagnosis of breast cancer. Acta Histochem 2016; 118: 544552. https://doi.org/10.1016/j.acthis.2016.05.002

[26] SAHIN S, ISIK GONUL I, CAKIR A, SECKIN S, ULUOGLU O. Clinicopathological Significance of the Proliferation Markers Ki67, RacGAP1, and Topoisomerase 2 Alpha in Breast Cancer. Int J Surg Pathol 2016; 24: 607-613. https:// doi.org/10.1177/1066896916653211
[27] OTTO T, SICINSKI P. Cell cycle proteins as promising targets in cancer therapy. Nat Rev Cancer 2017; 17: 93-115. https://doi.org/10.1038/nrc.2016.138

[28] WITZEL, II, KOH LF, PERKINS ND. Regulation of cyclin D1 gene expression. Biochem Soc Trans 2010; 38: 217-222. https://doi.org/10.1042/BST0380217

[29] QIE S, DIEHL JA. Cyclin D1, cancer progression, and opportunities in cancer treatment. J Mol Med (Berl) 2016; 94: 1313-1326. https://doi.org/10.1007/s00109-016-1475-3

[30] MOROY T, GEISEN C. Cyclin E. Int J Biochem Cell Biol 2004; 36: 1424-1439. https://doi.org/10.1016/j.biocel.2003.12.005

[31] BAI L, WANG S. Targeting apoptosis pathways for new cancer therapeutics. Annu Rev Med 2014; 65: 139-155. https:// doi.org/10.1146/annurev-med-010713-141310

[32] LIU X, DUAN C, JI J, ZHANG T, YUAN X et al. Cucurbitacin $\mathrm{B}$ induces autophagy and apoptosis by suppressing CIP2A/PP2A/mTORC1 signaling axis in human cisplatin resistant gastric cancer cells. Oncol Rep 2017; 38: 271-278. https://doi.org/10.3892/or.2017.5648

[33] SINHA S, KHAN S, SHUKLA S, LAKRA AD, KUMAR S et al. Cucurbitacin B inhibits breast cancer metastasis and angiogenesis through VEGF-mediated suppression of FAK/ MMP-9 signaling axis. Int J Biochem Cell Biol 2016; 77: 4156. https://doi.org/10.1016/j.biocel.2016.05.014

[34] JULIEN O, WELLS JA. Caspases and their substrates. Cell Death Differ 2017; 24: 1380-1389. https://doi.org/10.1038/ cdd.2017.44

[35] YANG B, YE D, WANG Y. Caspase-3 as a therapeutic target for heart failure. Expert Opin Ther Targets 2013; 17: 255263. https://doi.org/10.1517/14728222.2013.745513

[36] BOULARES AH, YAKOVLEV AG, IVANOVA V, STOICA BA, WANG G et al. Role of poly(ADP-ribose) polymerase (PARP) cleavage in apoptosis. Caspase 3-resistant PARP mutant increases rates of apoptosis in transfected cells. J Biol Chem 1999; 274: 22932-22940. https://doi.org/10.1074/ jbc.274.33.22932

[37] MAO D, QIAO L, LU H, FENG Y. B-cell translocation gene 3 overexpression inhibits proliferation and invasion of colorectal cancer SW480 cells via Wnt/beta-catenin signaling pathway. Neoplasma 2016; 63: 705-716. https://doi.org/10.4149/ neo_2016_507

[38] ZHENG HC, HE HY, WU JC, LI J, ZHAO S et al. The suppressing effects of BTG3 expression on aggressive behaviors and phenotypes of colorectal cancer: An in vitro and vivo study. Oncotarget 2017; 8: 18322-18336. https://doi. org/10.18632/oncotarget.15438

[39] AN Q, ZHOU Y, HAN C, ZHOU YB, LI F et al. BTG3 overexpression suppresses the proliferation and invasion in epithelial ovarian cancer cell by regulating AKT/GSK3beta/ beta-catenin signaling. Reprod Sci 2017; 24: 1462-1468. https://doi.org/10.1177/1933719117691143

[40] DU Y, LIU P, ZANG W, WANG Y, CHEN X et al. BTG3 upregulation induces cell apoptosis and suppresses invasion in esophageal adenocarcinoma. Mol Cell Biochem 2015; 404: 31-38. https://doi.org/10.1007/s11010-015-2363-9 